\title{
PENGUKURAN KINERJA MESIN PERUSAHAAN MENGGUNAKAN OVERALL EQUIPMENT EFFECTIVENESS DAN USULAN PERBAIKAN MENGGUNAKAN DIAGRAM SEBAB AKIBAT (FISH-BONE) PADA CV. JATI MAKMUR PASURUAN
}

\author{
Fredo Karismawan \\ Puspandam Katias \\ Departemen Manajemen Fakultas Ekonomi dan Bisnis Universitas Airlangga
}

\begin{abstract}
.
This study aims to to know costs inflicted of a system of preventive maintenance and maintenance of the breakdown and its effect on downtime. The research was done in the lumber cv. Jati prosper with the qualitative study approach uses the descriptive. Procedures data collection in penellitian it has several stages of, namely the preliminary survey, theoretical survey, and field study. The result from research found that among januari until december 2010 OEE range 65,093\% -81,175\%.after research found that two factors majority affect OEE value in CV.Jati Makmur two factors is reduce speed losses and setup and adjustment losses with proportion 45,83\% and 40,88\%.
\end{abstract}

Keyword: OEE (Overall Equipment Effectiveness), total productive maintenance, manufacturing performance

1, total produktif maintenance, kinerja manufaktur

\section{Pendahuluan}

Di era ini pertumbuhan penduduk di dunia pada umumnya dan indonesa pada kususnya mengalami kemajuan yang sangat pesat di berbagai sektor tak terkecuali di sektor perindustrian. Kayu merupakan komoditas yang cukup penting untuk menunjang pembangunan di kota-kota besar. Seiring berkembangnya tekhnologi dan peradaban manusia kini kebutuhan akan kayu semakin banyak, oleh karena itu banyak berdiri pabrik-pabrik kayu mentah maupun kayu jadi karena dinilai bisnis pada komoditas ini dinilai cukup potensial. Persaingan di komoditas ini tidak bisa dianggap remeh lagi karena banyaknya pesaing lama maupun baru.

Guna menghadapi hal ini sekarang perusahaan-perusahaan itu berlomba-lomba untuk memperbaiki mutu dan kualitas agar memperoleh keunggulan kompetitif sehingga dapat bersaing dengan pesaing-pesaing lama maupun baru yang bisa manimbulkan ancaman bilamana perusahaan tidak dapat bertahan menghadapi persaingan. Keunggulan kualitas dan mutu tidak diperoleh secara instan dan mudah, tentunya perusahaan harus melakukan pengkajian terhadap rencana bisnis mereka. 


\section{Fredo Kurniawan}

\section{Puspandam Katias}

Dunia bisnis saat ini kita mengenal istilah-istilah penting dalam studi untuk memajukan industri yang ada. Faktor manajemen operasional tidak kalah pentingnya dengan perkembangan perusahaan di sektor luar sebagai faktor penting untuk memperbaiki kinerja perusahaan di internal bisnis proses. Karena pada pada era lampau pemasaran dan citra perusahaan di luar dianggap faktor penting untuk kelangsungan perusahaan sehingga mereka melupakan berapa banyaknya biaya yang digunakan untuk operasional di dalam perusahaan itu sendiri.

Dalam proses produksi di zaman modern ini kebanyakan perusahaan yang sudah berkembang mulai menggunakan mesin produksi sesuai bidang nya masing-masing. PT. Makmur Cahaya Anugerah merupakan perusahaan yang bergerak di bidang manufaktur kayu dengan kapasitas produksi yang cukup besar sehingga memiliki banyak mesin produksi yang digunakan untuk mengolah kayu agar siap dikirim kepada konsumen dalam maupun luar negeri.

Sama hal nya dengan perusahaan-perusahaan manufaktur yang lain. Mesin pada perusahaan kayu ini tentunya memiliki kapasitas produksi dan spesialisasi masing-masing unit produksi. Seiring berkembangnya perusahaan dan pasar yang ada seringkali menimbulkan masalah-masalah baru pada bidang operasional internal perusahaan. Mulai dari masalah pekerja yang dinilai terlalu lambat sehingga tidak dapat memenuhi kebutuhan pelanggan tepat waktu hingga masalah tekhnis di bagian mesin yang sering mengalami kerusakan secara tiba-tiba sehingga memperlambat proses produksi (Aghezaff E.H :2007). sebenarnya sebagian dari hasil perawatan penocegahan itu dapat dilakukan pada saat jam istirahat/hari libur, bebrapa perawatan yang tidak terjadwal dapat mengganggu rencana produksi.

Tekhnologi merupakan satu-satunya faktor yang terus bisa dikembangkan untuk mendukung kemajuan industri. Sehingga seirama dengan majunya tekhnologi maka akan terjadi dorongan pula dengan kemajuan mesin-mesin industri yang ada. Sehingga mesin dengan sistem baru akan membutuhkan treatment dan kegunaan yang baru dengan segala keunggulan yang ditawarkan. (Madu, 1999; Cooke, 2000; Madu, 2000) menjelaskan bahwa perawatan peralatan dan kehandalan sistem merupakan faktor penting yang mempengaruhi kinerja perusahaan secara organisasi untuk peningkatan kualitas dan pelayanan yang tepat waktu kepada konsumen.

Biaya yang dikeluarkan perusahaan untuk produksi dengan mesin tentunya semakin ringan dibandingkan biaya tenaga kerja manual serta dapat meningkatkan kapasitas produksi perusahaan. Kendala dalam produksi mesin juga kerap dialami saat proses produksi sehingga memperlambat beberapa pekerjaan di manufaktur sehingga perusahaan harus mengganti atau memperbaki sistem ataupun mesin yang ada. (Fleischer : 2006) Kinerja dan daya saing perusahaan dipengaruhi oleh kehandalan layanan dan produktifitas peralatan dan mesin mereka. 


\section{Jurnal Manajemen Teori dan Terapan \\ Tahun 8. No. 1, April 2015}

Ini berarti perusahaan menghadapi masalah yang cukup berarti, biaya perawatan atau manajemen pemeliharaan merupakan pekerjaan rumah baru bagi di perusahaan. Perbaikan peralatan dan perlengkapan merupakan faktor penting yang mempengaruhi kemampuan organisasi untuk meningkatkan kualitas dan kecepatan pelayanan kepada konsumen guna menaghadapi persaingan (Peter, LilianePintelon, Ludo Gelders, HarryMartin 2010)

Oleh karena itu kita mengenal Manajemen pemeliharaan (maintanance). Dalam beberapa perusahaan manajemen pemeliharaan seringkali dianggap sebagai tindakan pertama setelah terjadinya kerusakan, namun makna sesungguhnya dari manajemen pemeliharaan adalah mencegah terjadinya kerusakan (Batty 110:1979).

Maintanance seringkali disepelekan sehingga membuat perusahaan mengeluarkan biaya lebih untuk pembelian atau pengadaan mesin baru karena adanya kerusakaan tiba-tiba pada mesin produksi perusahaan dan masalah merembet kepada produktivitas manufaktur dan suplai perusahaan terhadap konsumen. Selama ini perusahaan seringkali tidak menyadari hal ini sehingga tidak dijadikan kajian atau evaluasi kinerja mesin yang digunakan oleh perusahaan. Sebenarnya hal ini bisa diatasi dengan mengadakan tindakan preventive atau yang kita kenal dengan TPM ( Total Producventive Maintenance).

Untuk mengimplementasikan proyek total productive maintenance perlu adanya sinergi dan penyesuaian dari perusahaan. Hal ini berkaitan dengan strategy perusahaan dan strategi produksi dari perusahaan agar program maintenance berjalan dengan baik dan berhasil mereduksi biayabiaya yang dinilai terlalu tinggi. Keterlibatan karyawan lantai dan operator mesin juga merupakan hal yang penting dalam penerapan Total Productive Maintenance.

Ada beberapa metode yang digunakan saat ini dalam mengatasi masalah pemeliharaan pada mesin-mesin pabrik seperti metode fish-bone dan six-big losses yang akan digunakan untuk menganalisa penyebab dan faktor-faktor yang memperlambat ataupun mengganggu prosees produksi.

Pembobotan terhadap faktor faktor yang mempengaruhi kinerja mesin perusahaan juga sangat penting guna fokus perusahaan terhadap perbaikan mana yang harus didahulukan. Pengukuran kinerja terhadap mesin dan peralatan perusahaan kita kenal dengan metode Overall Equipment Effectiveness. Pembobotan dengan OEE berfokus pada 3 hal yaitu ketersediaan mesin, kinerja mesin, dan kualitas hasil produk.

Total dari formulasi Overall Equipment Effectiveness skala internasional adalah $85 \%$ secara total dan apabila perusahaan berada dibawah itu bisa dikatakan perusaan perlu memperbaiki performa nya 


\section{Fredo Kurniawan}

\section{Puspandam Katias}

dengan menganalisa faktor-faktor yang memperngaruhi nilai OEE. Dari nilai yang telah diperoleh dari hasil formulasi data-data kinerja perusahaan yang dihitung dengan OEE maka dapat diketahi six big losses yang di diderita oleh perusahaan. Setelah hasil ditemukan, menggunakan metode ini dan didukung oleh Pareto Chart untuk pembobotan faktor dengan nilai paling besar maka diharapkan perusahaan akan tau faktor mana yang hendaknya didahulukan untuk diadakan perbaikan.

\section{Kinerja mesin}

Kinerja mesin bisa dikatakan sebagai faktor utama yang sangat membantu perusaahaan untuk memenuhi pasar dengan demand yang tinggi. Fungsi mesin terkadang mengalami penurunan kinerja seiring bertambanya usia mesin dan juga penggunaan oleh sumber daya manusia yang kurang berpengalaman. Perlu adanya perbaikan secara berkelanjutan dan periodic demi kelangsungan efektifitas mesin. Perawatan yang baik berasumsi bahwa tujuan pemeliharaan dan strategi tidak ditentukan secara terpisah tetapi dalam beberapa cara berasal dari faktor-faktor seperti kebijakan perusahaan, kebijakan manufaktur dan lainnya yang berpotensi bertentangan tuntutan dan kendala dalam perusahaan (Swanson 1997; Johnsson and Lesshamar, 1999; Swanson 2001; Pinjala et al., 2006).

Pemeliharaan juga mempertimbangkan berbagai aspek perusahaan mulai dari efektifitas dan efisien. Tujuan pemeliharaan terkait dengan pencapaian target produksi (melalui ketersediaan tinggi) pada kualitas yang diperlukan, dan dalam kendala kondisi sistem dan keamanan. Selanjutnya, sumber daya pemeliharaan dimanfaatkan sehingga peralatan manufaktur berada dalam kondisi yang prima (Dekker, 1996).

\section{Perawatan (Maintenance)}

Maintenance merupakan sebuah fungsi di dalam suatu industri manufaktur yang sama seperti fungsi lainya di dalam sebuah proses produksi. Perawatan didefiniskan sebagai kombinasi dari semua aktifitas tekhnik dan asosiasi administratif yag dibutuhkan untuk kebutuhan peralatan, instalasi dan aset fisik lainya (BSI, 1984; Pintelon et al., 1997; Pintelon and VanPuyvelde, 2006).

Moudbray dalam tunjungsari 2013 mendefinisikan perawatan sebagai pelaksanaan aktiviitas yang memastikan peralatan fisik terus bekerja sebagaimana penggunanya menginginkan peralatan itu bekerja. Tsang dkk (1999) berpendapat bahwa perawatan merupakan proses rutin yang terus bekelanjutan untuk menjaga aset atau mesin dalam kondisi tetap normal sehingga dapat mengantarkan performa dan servis yang diharapkan.

\section{Total Preventive maintenance}

Menurut Siiichi Nakajima (1988) mendefinisikan Total Productive Maintenace (TPM) sebagai suatu pendekatan yang inovatif dalam maintenance dengan cara mengoptimasi keefektifan peralatan serta mengurangi/ menghilangkan kerusakan mendadak (breakdown) dengan melakukan identifikasi terlebih dahulu. Dengan kata lain Total Productive Maintenance sering didefinisikan sebagai productive maintenance yang dilaksanakan oleh seluruh pegawai, didasarkan pada prinsip bahwa peningkatan 


\section{Jurnal Manajemen Teori dan Terapan \\ Tahun 8. No. 1, April 2015}

kemampuan peralatan harus melibatkan setiap orang di dalam organisasi, dari lapisan bawah sampai manajemen puncak.

TPM telah diakui secara luas sebagai tindakan strategis untuk meningkatkan kinerja manufaktur dengan meningkatkan efektivitas sarana produksi. Karena penerapan TPM sangan membantu perampingan manufaktur dan fungsi bisnis lainya dalam menghasilkan perbaikan secara kontinyu di rantai bisnis mulai hulu ke hilir. Strategi implementasi TPM mengurangi terjadinya kerusakan mesin yang tak terduga yang mengganggu proses produksi dan menyebabkan kerugian yang dapat melebihi jutaan dollar per tahun (Dossenbach, 2006)

TPM dirancang untuk mengoptimalkan fungsi peralatan dan mesin serta jam kerja yang ada dengan cara mengadakan sistem perawatan yang komprehensif terhadap peralatan. Dengan perawatan yang komprehensif diharapkan fungsi mesin dan SDM yang ada dapat bekerja secara optimal sehingga berpengaruh terhadap fungsi bisnis yang lain. Program TPM yang efektif dapat memfasilitasi peningkatan kemampuan organisasi di berbagai dimensi (Wang, 2006).

Secara menyeluruh definisi total productive maintenance menurut Nakajima 1988 mencakup lima elemen berikut :

1. TPM bertujuan untuk menciptakan suatu sistem preventive maintenance (PM) untuk memperpanjang umur penggunaan mesin peralatan.

2. TPM memaksimalkan efektifitas mesin peralayan secara keseluruhan (overall effecttiveness)

3. TPM dapat diterapkan dalam berbagai departemen (seperti engineering, bagian produksi, bagian maintenance)

4. TPM melibatkan semua orang/karyawan mulai dari manajemen tertinggi hingga para operator/karyawan lantai pabrik.

5. TPM merupakan pengembangan dari sistem maintenance berdasarkan PM melalui manajemen motivasi: autonomous small group activities.

Subyek utama yang menjadi ide dasar dari kegiatan TPM adalah manusia dan mesin. Dalam hal ini diusahakan agar dapat mengubah pola pikir manusia terhadap konsep pemeliharaan yang selama ini biasa dipakai. Pola pikir "Saya menggunakan peralatan dan orang lain yang memperbaiki" diubah menjadi "saya memperbaiki peralatan saya sendiri". Untuk itu para karyawan dituntut untuk dapat belajar menggunakan dan merawat mesin/peralatan dengan baik dan dengan demikian perlu disiapkan suatu sistem pelatihan(trainning) yang baik.

\section{Overall equipment effectiveness (OEE)}

Overall equipment effectiveness adalah sebuah metode pengukuran dasar untuk pengukuran kinerja. (Muchiri and Pintelon,2008) menyatakan "OEE metrik mendukung manajemen pemeliharaan dalam pengukuran peralatan ketersediaan dan perencanaan tingkat, yang merupakan fungsi dari yang direncanakan dan masing-masing downtime yang tidak direncanakan". Sedangkan Dal,2000 telah menyatakan bahwa OEE dapat digunakan sebagai standart untuk mengukur kinerja awal dari peralatan pabrik secara keseluruhan. Dal telah menggunaka OEE untuk menerapkan TPM dan meningkatkan kinerja mesin secara individu dengan mengurangi kerugian yang bersangkutan dengan peralatan. Hal ini 


\section{Fredo Kurniawan}

\section{Puspandam Katias}

dikarenakan OEE mampu menyajikan struktur kerugian dalam format pohon (sampai mencapai tingkat akar) bagi mesin produksi.

Dalam penelitian Ljunberg (1998) menyatakan bahwa definisi OEE merupakan metode digunakan sebagai alat Ukur (metric) dalam penerapan program TPM guna menjaga peralatan pada kondisi ideal dengan menghapuskan six big losess peralatan.

\section{Fish-bone diagram}

Metode kerja lingkungan kerja

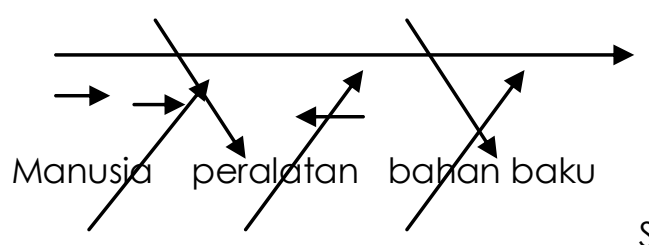

Sumber, Ghaiter : 2011

Dari gambar diagram fishbone diatas terlihat bahwa faktor penyebab masalah antara lain terdiri dari material/bahan baku, mesin, manusia, lingkungan dan metode ataupun sistim. Semua yang berhubungan dengan material, mesin, manusia, lingkungan dan metode yang saat ini dituliskan dan dianalisis faktor mana yang teridentifikasi menyimpang dan berpotensi terjadi masalah. Ketika sudah ditemukan satu atau beberapa penyebab jangan puas sampai disitu, karena ada kemungkinan masih ada akar penyebab di dalamnya yang tersembunyi dan belum teridentifikas.

\section{Pareto chart}

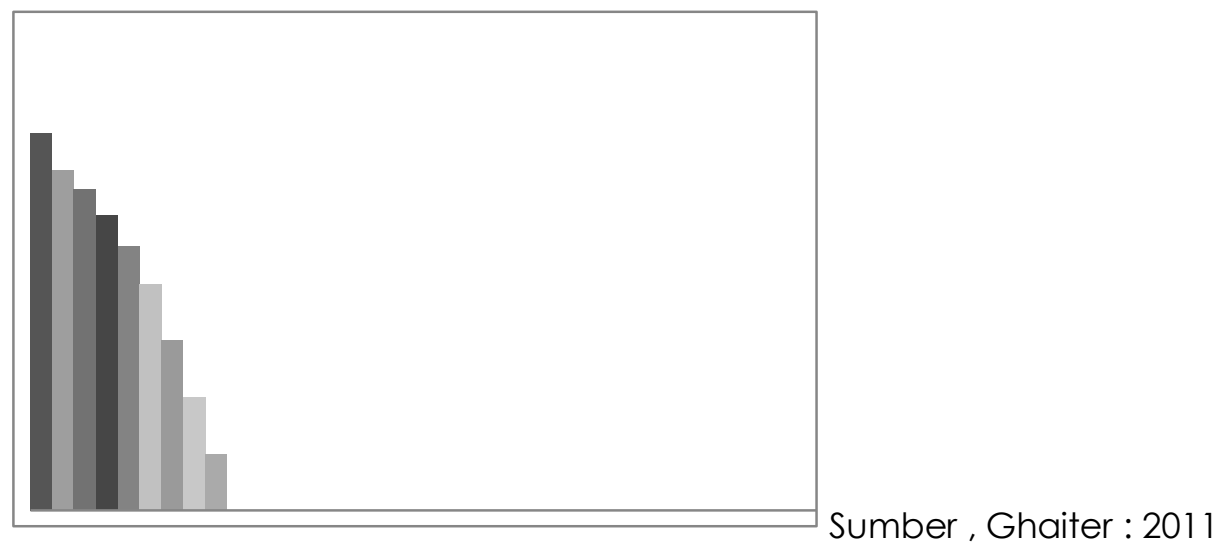

Langkah-langkah yang digunakan dalam membuat suatu pareto analisys (foster, 2004, 312)

1. Menggumpulkan kategori data yang berkaita dengan masalah kualitas.

2. Menggambar grafik frekuensi data.

3. Fokus pada bar tertinggi di tabel frekuensi pertama ketika memecahkan masalah.

\section{Metode Penelitian}

Pendekatan penelitian ini adalah kualitatif dengan menggunakan metode deskriptif. Menurut Sugiyono (2009: 2014) metode penelitian kualitatif adalah metode penelitian yang digunakan untuk meneliti pada kondisi obyek yang alamiah dimana peneliti sebagai instrument kunci, pengambilan sampel sumber data dilakukan secara purpesive dan snowball, tekhnik pengumpulan data dengan trianggulasi atau gabungan, analisis data bersifat induktif atau kualitatif, dan hasil penelitian lebih menekankan makna dari 


\section{Jurnal Manajemen Teori dan Terapan \\ Tahun 8. No. 1, April 2015}

pada generalilsasi. Prosedur pengumpulan data pada penellitian ini memiliki beberapa tahapan, yaitu survey awal, survey teoritis, dan studi lapangan.

\section{Hasil dan Bahasan}

Dari hasil penelitian yang dilakukan pada CV. Jati Makmur Pasuruan mengenai efektivitas kinerja mesin yang diukur dengan metode Overall Equiptment Effectiveness (OEE) maka dapat disimpulkan sebagai berikut.

1). Berdasarkan hasil perhitungan nilai Overall Equiptment Effectiveness (OEE) pada CV. Jati Makmur Pasuruan menunjukkan bahwa nilai OEE masih berada dibawah standart JPIM . hal ini dikarenakan untuk peridoe januari hingga desember 2014 nilai OEE berkisar antara 65,093\% Sampai 81,175\%. Dimana nilai OEE terbesar ada pada periode bulan Agustus 2014. Nilai availability pada periode januari - Desember 2014 berkisar antara 85,902\% sampai 93,694\%. Nilai performance efficiency periode Januari -Desember 2014 berkisar antara $70,125 \%$ hingga $92,384 \%$ sedangkan untuk rate of quality product periode Januari Desember 2014 berkisar antara 91,98\% hingga 100\%. Rata-rata Overall Equiptment Effectiveness pada periode Januari - Desember 2014 adalah 72,808\%

2). Setelah dilakukan pengukuran diketahui bahwa selama periode Januari - Desember 2014 ditemukan dua faktor yang berkaitan erat terhadap rendahnya nilai OEE di CV. Jati Makmur yaitu Reduced Speed Loss dan Setup and adjustment loss dengan masing-masing presentase 45,83\% dan 40,88\%. Tidak tepatnya pemasangan dan pemeliharaan mesin dan peralatan tidak saja menyebabkan menurunya kecepatan produksi mesin, hasil perbaikan yang dapat ditempuh perusahaan untuk meminimalisir terjadinya hal tersebut adalah dengan memberikan perhatian dan perawatan khusus terhadap mesin-mesin yang sudah tua dan harus mendapatkan perawatan lebih. Untuk faktor setup and adjustment loss sendiri seharusnya karyawan yang baru masuk atau kurang berpengalaman didampingi oleh mandor sehingga proses pergantian bahan produksi dapat berjalan dengan cepat. Pergantian mesin secara rutin hendaknya juga dilakukan untuk mencegah terjadinya kerusakan/kemacetan mesin secara tiba-tiba. Dengan cara demikian diharapkan terjadinya kerusakan mesin dan peralatan secara tiba-tiba dapat diminimalisir serta dapat meningkatkan tingkat kecepatan produksi.

\section{Saran}

Beberapa saran yang diharapkan dapat memberikan masukan dan manfaat bagi perusahaan berdasarkan hasil penelitian ini adalah :

1. Dalam upaya peningkatan efektivitas penggunaan mesin sebaiknya perhitungan OEE pada setiap mesin senantiasa dilakukan dalam periode tertentu oleh perusahaan untuk memperoleh data yang representative untuk perawatan dan perbaikan secara kontinyu agar perusahaan dapat mengetahui tingkat produktivitas mereka.

2. Untuk menghilangkan atau meminimalkan faktor six big losses yang terjadi, perusahaan dapat menerapkan autonomus maintenance yang bertujuan mendeteksi secara lini ketidaknormalan yang terjadi pada suatu mesin industri, mungkin perusahaan mengorbankan beberapa waktu untuk melatih karyawan-karyawan namun untuk kedepanya karyawan bisa memperbaiki sendiri mesin yang mereka jalankan sehingga kerusakan mesin dapat dicegah guna meningkatkan produktifitas dan efisiensi produksi. 


\section{Fredo Kurniawan}

Puspandam Katias

\section{Saran bagi penelitian selanjutnya}

Bagi penelitian selanjutnya disarankan agar membahas beserta efektifitas para pekerja dikaitkan dengan OEE berserta proporsi ukuran masing-masing prosentase pekerja. Diharapkan pada penelitian selanjutnya dapat lebih berpengaruh langsung dan terlihat signifikan bagi pengembangan efektivitas perusahaan dari segi waktu dan biaya.

\section{Pustaka Acuan}

Aghezzaf E.H. 2007. An Integrated Production And Preventive Maintenance Planning Model. European Journal of Operational Research 181 (2007) 679-685

Dekker, R., 1996. Application Of Maintenance Optimization Models: A Review And Analysis. Reliability Engineering and System Safety 51, 229-240.

Dossenbach, T. (2006), Implementing Total Productive Maintenance: A Successful TPM Program Will Help You Eliminate Defects, Machine Breakdowns And Accidents, Wood and Wood Products, Vol. 111 No. 2, pp. 29-32.

Fore, S. et al. 2010. Improvement of Overall Equipment Effectiveness through Total Productive Maintenance. World Academy of Science, Engineering and Technology Vol:4 2010-01-20.

Foster, S. Thomas. 2004. Managing quality, an integrative approach. Second edition. New jersery: Prentice hall.

Gaither, N. et. al. 2006. "Operation management 9th edition. USA.

Ljunberg, O. 1998. Measurement of Overall Equiptment Effectiveness as a basis for TPM Activities. International journal of operation \& production management. Vol. 18 No.5. pp.495-507.

Kattila, P. 2010. Applying Total Productive Maintenance - TPM principles in the manufacturing systems. Technical Report Lulea Teknisa University. Pp.19

Muchiri, P. et. al. 2010. Development of maintenance function performance measurement framework and indicators. Int. J. Production Economics. p.1

Nakajima, S. 1988. "Introduction to TPM:Total Productive Maintenance." Productivity Press: Cambridge.Massachusetts.

Noon, M. et al. 2000. FADS, Techniques and Control: The Competing Agendas of TPM and Tecax at the Royal Mail (UK). Journal of Management studies. Vol. 37 No.4. p. 499

Sugiyono. 2009. "Metode penelitian bisnis (pendekatan kuantitatif, kualitatif, dan R\&D) (cetakan ke -13)". Bandung: IKAPI

Swanson, L. 2001. Linking maintenance strategies to performance. Int. J. Production Economics 70 (2001) pp.237-44,USA. 
Tsang, A.H.C. et al. 1999. Measuring Maintenance Performance: a holistic approach.

Wang, F.K. 2006. Evaluating the Efficiency of Implementing Total Productive Maintenance. Total Quality Management. Vol. 17 No. 5. pp. 655. 